\title{
Simulation of Lake Water Source Heat Pump System Based on TRNSYS Chunzhen Qiao ${ }^{a}$, Shaopeng Yang $^{b}$ and Yuqing Zhao ${ }^{c}$ School of civil engineering, North China University of Technology, Beijing 100144, China ajoecz1221@sina.com, ${ }^{b}$ 542502559@qq.com, ${ }^{\mathrm{c} z y q b j @ 126 . c o m}$
}

Keywords: Lake water source heat pump; Trnsys; Energy analysis.

Abstract. The compression heat pump system using lake water as a heat source was designed and analyzed. With an example of such office building in Lianyungang City in China, by using trnsys combined with survey analysis, the energy consumption was simulated and analyzed. As a result, it seemed to illustrate that the yearly mean COP of heat pump is about 3.6. This heat pump system which used lake water can therefore be effectively applied for space heating and cooling in regions like as Lianyungang.

\section{Introduction}

Surface water-source heat pump is a technology that uses the low resources of Earth's surface shallow water (ground water, rivers and lakes) in absorption of solar energy and geothermal heat, and using principles of heat pump through a small number of high electric power input to make low heat transfer to high heat [1].

Simply speaking, lake water source heat pump system applies lake water as hot and cold source. In winter, heat pump absorbs heat from lake water for their buildings heating; on the other hand, in summer, heat pump absorbs heat from the buildings and transfers it to the lake. Application of only a hardware system, throughout transformation of a condenser and evaporator in different seasons, we can complete the conversion of refrigeration and heating functions [2].

\section{Mathematical Model of Lake Water's Temperature}

Lakes, reservoirs and other water surface temperature changes is a process of water - gas interface complex heat exchange. Water absorbs and reflects the sun (short wave), atmosphere (long wave ) radiation heat flux, and dissipating heat by evaporation, convection, radiation, and other 3 forms into the atmosphere, when the water get net radiation heat flux is greater than the total heat flux, the water's temperature increases. Therefore, the natural water temperature changes, in addition to the influence of radiation heat, the water surface of the cooling capacity is also an important factor for restricting water temperature changes.

The heat of the solar radiation is the same heat source of air and water, and both of them are positively related to the size of solar radiation heat flux, air increases the solar radiation heat, the water absorption of solar radiation heat will increase.

Therefore, on the basis of the actual data analysis, there maintains close relationship between water temperature and air temperature. As a result, it is very important to establish the relationship between air temperature and water temperature, which can not only reflect the direct influence by the water temperature, but also includes the effect of solar radiation.

The humidity in the air is high, so the water molecules that escape from the water are not easy to be absorbed by the air, and when the water molecules escaping from the surface of the water all return to the water body, the evaporation and heat dissipation function of the water surface is stopped. Therefore, the humidity in the air has an inhibitory effect on evaporative cooling, The humidity in the air increases, the natural water temperature presents a rising trend.

It is obvious that the wind speed has a big impact on evaporative cooling, the size of the average wind speed above the surface of the water, affecting the water-air interface of turbulent diffusion intensity. In the case of other meteorological conditions unchanged, the wind speed increased, the natural water temperature showed a downward trend. 
The factors that affect the water surface evaporation and heat dissipation include air pressure, water quality, temperature difference between water and air, etc. These factors are not considered because of the slightly influence of these factors on natural conditions, or some factors have been covered by others [3].

A new formula for calculating the lake (reservoir) of natural water temperature that based on the analysis of the observed data from various regions, such as temperature, relative humidity and wind speed has been established in the literature [4].

\section{错误!未找到引用源。}

$\mathrm{T}_{\mathrm{a}}$ - Temperature at 1.5 meters above the water surface

$\mathrm{r}$ Relative humidity at 1.5 meters above the water surface

$\mathrm{w}_{150}$ The average wind speed at 1.5 meters above the water surface.

There is an artificial lake near the building, and the water quality of the lake is good. The variations of the lake water's temperature within hours in a year are shown in Fig. 1.

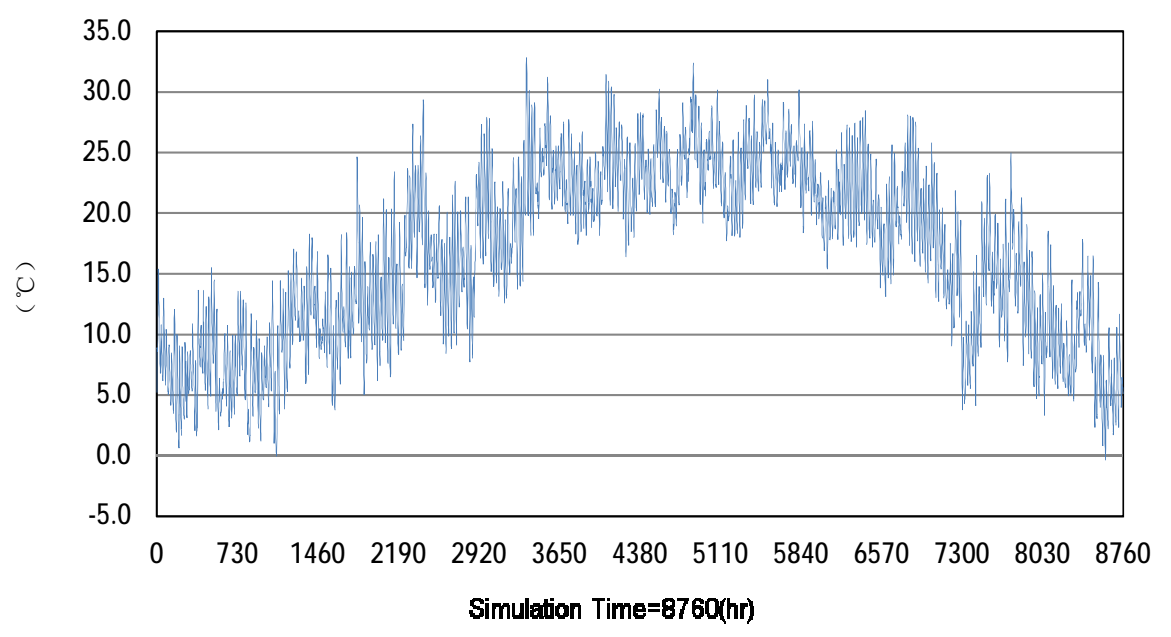

Fig. 1 The variation regulation of lake water's temperature in one year

\section{Simulation of Lake Water Source Heat Pump System}

\section{Introduction of TRNSYS 16}

This study employed the well-known TRNSYS 16 as a simulation tool for theoretical analysis.

TRNSYS is a complete and extensible simulation environment for the transient simulation of systems, including multi-zone buildings. A TRNSYS project is typically setup by connecting components graphically in the Simulation Studio. Each Type of component is described by a mathematical model in the TRNSYS simulation engine and has a set of matching Proforma's in the Simulation Studio. The proforma has a black-box description of a component: inputs, outputs, parameters, etc[5].

TRNSYS components are often referred to as Types. The Multizone building model is known as Type 56. The Simulation Studio generates a text input file for the TRNSYS simulation.

Meteorological parameter information in Lianyungang area

Building energy consumption simulation is necessary for the design of building energy saving, the basis of which is reliable hourly data of a whole year. Meteonorm is a comprehensive meteorological reference. It gives you access to a catalogue of meteorological data for solar applications and system design at any desired location in the world. It can be used as a reference for building design, heating \& cooling systems, solar energy system design, etc[6].

In this paper, Meteonorm 7 software was used to generate the weather conditions throughout the year in Lianyungang, and as a basis for the use of simulation. Figure 2 shows the local annual outdoor temperature. 


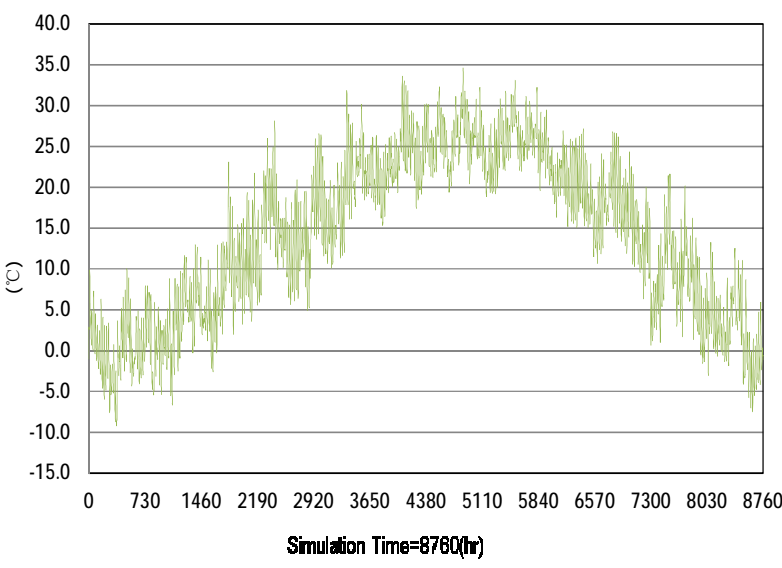

Fig. 2 The local annual outdoor temperature.

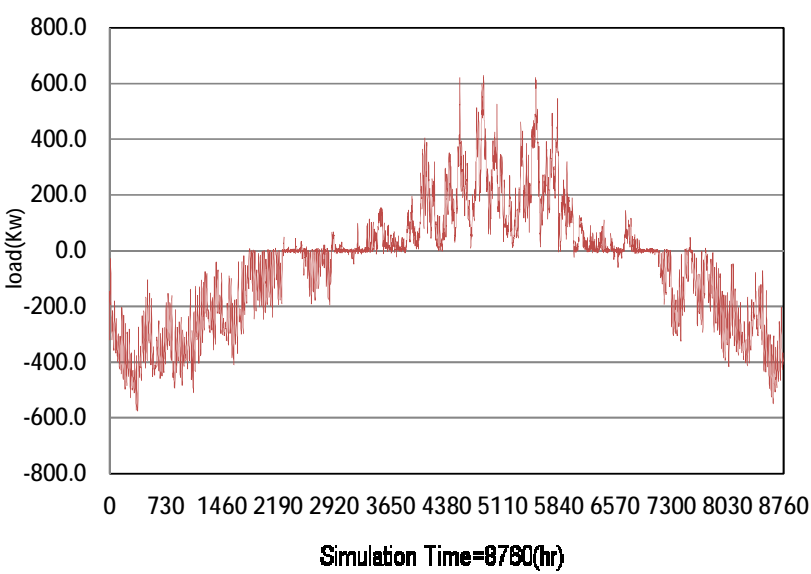

Fig. 3 The annual load simulation results

\section{Basic Building Information}

Building hourly load calculation is the basis for dynamic simulation analysis of HVAC system. This paper will take a single low density building in Lianyungang area as the research object, using TRNSYS software to simulate the hourly load of the building. The building is a typical corridor type office building, a building area of $8057 \mathrm{~m}^{2}$, North and South orientation. The building has six layers, each layer of $3.5 \mathrm{~m}$, and the South and North walls of the window wall ratio was 0.22 . Heat transfer coefficient of building envelope is shown in Table 1, and the design of the heat load is $918 \mathrm{~kW}$ when heat load index for $60 \mathrm{~W} / \mathrm{m}^{2}$ [7].

Table 1.Heat transfer coefficient of building envelope

\begin{tabular}{ll}
\hline $\begin{array}{l}\text { Type of retaining } \\
\text { structure }\end{array}$ & $\begin{array}{l}\text { heat transfer coefficient } \\
\mathrm{w} /\left(\mathrm{m}^{2} \cdot \mathrm{k}\right)\end{array}$ \\
\hline Air conditioning room & 0.85 \\
partition & \\
Exterior Window & 2.79 \\
Roofing & 0.37 \\
Ground & 0.25 \\
Floor slab & 0.56 \\
Exterior Wall & 0.63 \\
\hline
\end{tabular}

\section{Simulation of Building Load}

To simulate the lake water source heat pump system, we combined some little systems together. According to the building information and meteorological information we set up a system diagram first, and the structure of the annual load is simulated. Fig.3 shows the structure of the annual load simulation results.

\section{Construction and Analysis of Lake Water Source Heat Pump System}

With water temperature throughout the year and building the hourly load as the foundation, established the lake water source heat pump system diagram. Fig.4 shows the configuration of the TRNSYS desk for the overall system.

The annual hourly energy consumption change of the water source heat pump can be obtained, as shown in Figure 5. As can be seen in Figure 5, due to the low water temperature in the winter, the heat pump energy consumption is higher. In summer, the lake water source heat pump power consumption is significantly less than winter's, while in the transition season only consume very little power.

Figure 6 shows that when the lake water source heat pump in the operation and shutdown state, the building's indoor temperature changes in the whole year, after opening the lake water source heat pump, the indoor temperature is maintained at 20 to $30{ }^{\circ} \mathrm{C}$. 




Fig. 4 The configuration of the TRNSYS desk for the overall system.

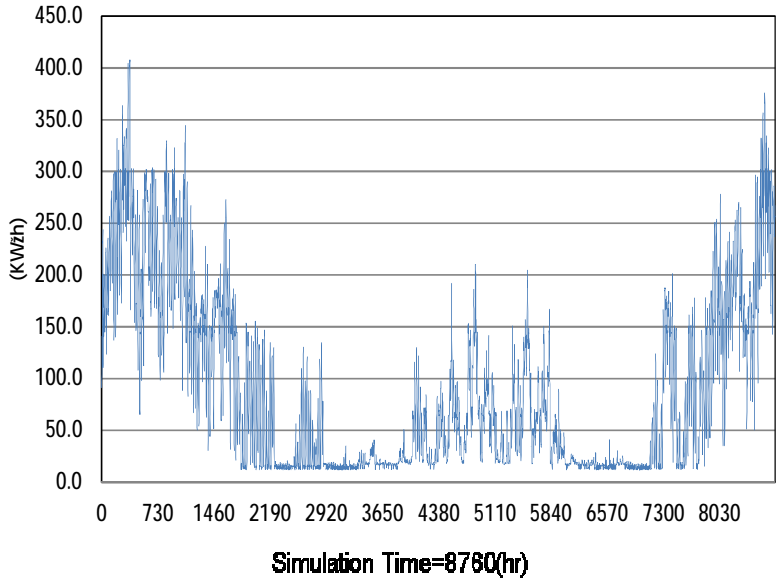

Fig. 5 The annual hourly energy consumption change of lake water source heat pump

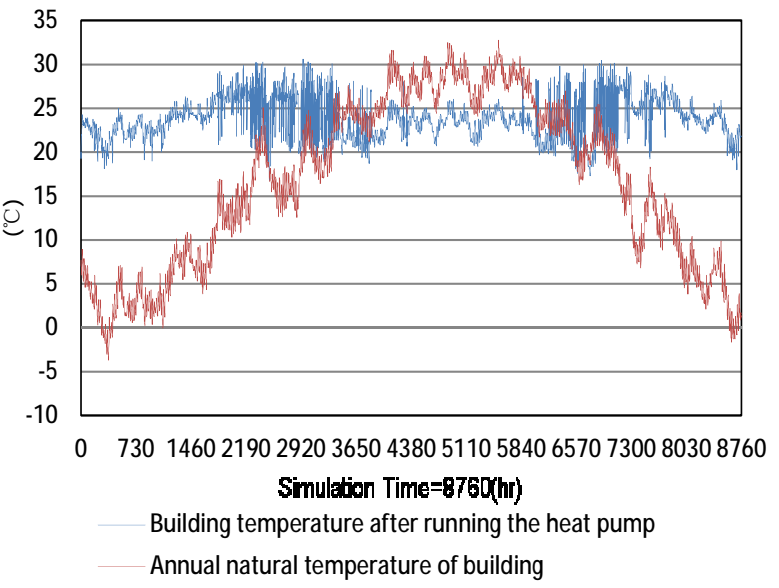

Fig. 6 The building temperature when the lake water source heat pump in operation and shutdown.

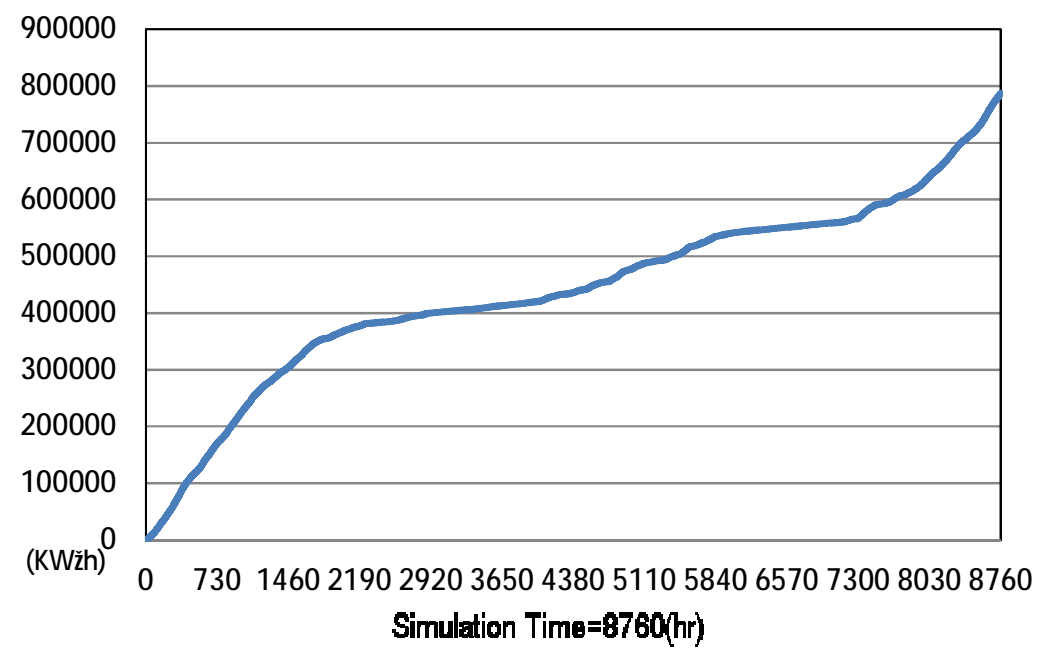

Fig. 7 The annual energy consumption 
Figure 7 shows the annual energy consumption of lake water source heat pump in order to maintain the stability indoor temperature of the building. It can be found that the energy consumption grows faster in winter, while in summer and transition seasons, the growth is relatively slow. The whole years' energy consumption of lake water source heat pump is $787273.6 \mathrm{~kW} \cdot \mathrm{h}$, the sum of the refrigeration and heating is $2887193 \mathrm{~kW} \cdot \mathrm{h}$, the yearly mean COP of lake water heat pump is about 3.6. And the yearly mean COP of air source heat pump is about 2.9.

\section{Conclusions}

In this study, a heat pump system for space heating and cooling using lake water, as a heat source, was designed and an energy analysis was performed in order to evaluate the efficiency of the system. The system was designed to use a simple method which does not control the temperature of lake water flowing into the heat pump's condenser and evaporator. Energy analysis was performed by computer simulation using TRNSYS. The analytic results are as follows:

First, the yearly mean operating COP of the heat pump is 3.6, which has better performance than that of conventional heat pump system using ambient air heat source.

Second, the heat pump's energy consumption grows faster in winter, while it is relatively slow in summer and transitional seasons.

Third, the energy consumption of the lake water source heat pump is $787273.6 \mathrm{~kW} \cdot \mathrm{h}$ for the whole year, which can completely satisfy both the heating and cooling system.

Therefore, it can be concluded that this system is suitable for areas with similar climate just as Lianyungang. On the other hand, the cost saving is another advantage of the system.

\section{Acknowledgements}

This paper is financially supported by the Training Program for Outstanding Young Teachers of North China University of Technology (XN072-029).

\section{References}

[1] Lv N, Zhang Q, Chen Z, et al. Building Simulation. (2016), p.1-9

[2] Information on http://bbs.yylstudy.com

[3] Li Y, Liu X, Liu Z: Theoretical analysis and practice about comprehensive energy utilizing systems of lake water source heat pump (International Conference on IEEE, 2011) p.1355-1359

[4] Zhenying Bai: A new formula for calculating natural water temperature of lakes (hydrology, 1999) p. 3. In Chinese.

[5] S.A. Klein: TRNSYS 16 Reference Manual (Solar Energy Laboratory, University of Wisconsin, Madison, USA, 2005).

[6] Information on http://www.meteonorm.com/en/features

[7] China Institute of Building Standard Design \& Research: National Technical Measures for Design of Civil Construction Special Edition-Energy Conservation: Heating, Ventilation and Air Conditioning (CHINA PLANNING PRESS, 2007). In Chinese. 